\title{
An educational programme for primary healthcare providers improved functional ability in older people living in the community
}

Vass M, Avlund K, Lauridsen J, et al. Feasible model for prevention of functional decline in older people: municipality-randomized, controlled trial. J Am Geriatr Soc 2005;53:563-8.

Does an educational programme for healthcare providers in routine primary care improve functional ability and reduce nursing home admissions and mortality in older people?

\section{METHODS}

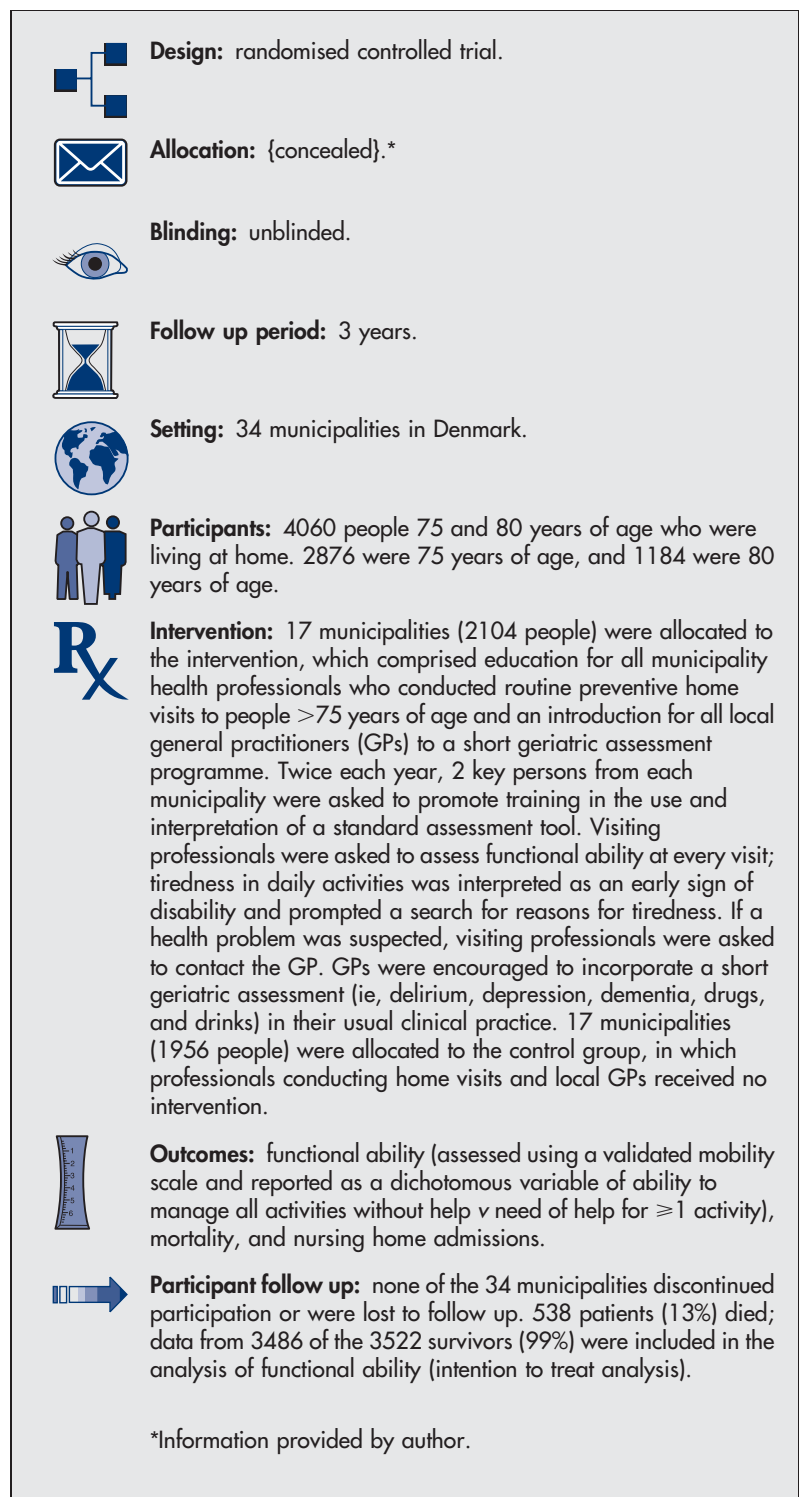

For correspondence: Dr $M$ Vass, Institute of Public Health, University of Copenhagen, Copenhagen, Denmark. m.vass@dadlnet.dk

Sources of funding: Danish Ministry of Social Affairs, Danish Medical Research Council, Research Foundation for General Practice and Primary Care, Eastern Danish Research Forum, and County Value-Added Tax Foundation.

\section{MAIN RESULTS}

At 3 years, people in the intervention group had higher functional ability than those in the control group (adjusted odds ratio [OR] 1.20, $95 \%$ CI 1.01 to 1.42); age stratified analysis (adjusted for sex, municipality pairs, functional status, and living alone at baseline) showed similar results in the cohort of people who were 80 years of age at baseline (OR 1.53, CI 1.12 to 2.09) but not in the cohort of people who were 75 years of age at baseline (OR 1.03, CI 0.83 to 1.28). The intervention and control groups did not differ for mortality (adjusted relative risk [RR] 1.06, CI 0.87 to 1.28 ) or nursing home admissions (adjusted RR 0.74, CI 0.50 to 1.09).

\section{CONCLUSION}

At 3 years, an educational programme for healthcare providers in routine primary care improved functional ability in older people living in the community but did not reduce nursing home admissions or mortality.

\section{Commentary}

The study by Vass et al makes an important contribution to our knowledge of the effectiveness of preventive home visits in delaying or preventing functional impairment in elderly people. The study was well designed and had an adequate sample size.

It should be noted that the study was done in Denmark, where all citizens $\geqslant 75$ years of age are offered 2 annual preventive home visits. Visiting professionals in the intervention group received instruction on the use and interpretation of a standardised tool for assessing functional ability. The authors did not describe the content of the usual (control) preventive visits, but one would expect healthcare professionals to assess functional decline and offer guidance and support during routine health checks in people $\geqslant 75$ years of age. If this were the case, it would tend to mask the benefits of the intervention.

Vass et al found that the intervention was more beneficial for participants who were 80 years of age than for those who were 75 years of age. They also recommend focusing on the early triggers of functional decline when function is more modifiable. In contrast, a systematic review by Stuck et al concluded that mortality risk was modifiable in people $<80$ years of age but not in those $\geqslant 80$ years of age, ${ }^{\prime}$ although much of the evidence in this review came from countries without routine preventive home visits.

Only $60 \%$ of people $\geqslant 75$ years of age accepted and received the core preventive home visits. Further research is required to determine why $40 \%$ of people refused this service because even the most beneficial intervention will have no effect if it is refused. In most countries, preventive programmes are not routinely offered to elderly people. The study by Vass et al supports the use of programmes that include an assessment of functional decline and additional focused education for healthcare professionals working with older people.

Dorothy A Forbes, RN, PhD University of Western Ontario London, Ontario, Canada

1 Stuck EA, Egger M, Hammer A, et al. Home visits to prevent nursing home admission and functional decline in elderly people: systematic review and meta-regression analysis. JAMA 2002;287:1022-8. 